\title{
Impact of Temperature on the Strength Development of the Tailing-Waste Rock Backfill of a Gold Mine
}

\author{
Bin Han, ${ }^{1}$ Shengyou Zhang, ${ }^{2,3}$ and Wei Sun $\mathbb{D}^{2,3}$ \\ ${ }^{1}$ School of Civil and Environmental Engineering, University of Science and Technology Beijing, Beijing 100083, China \\ ${ }^{2}$ Faculty of Land Resources Engineering, Kunming University of Science and Technology, Kunming 650093, China \\ ${ }^{3}$ Yunnan Key Laboratory of Sino-German Blue Mining and Utilization of Special Underground Space, Kunming 650093, China
}

Correspondence should be addressed to Wei Sun; kmustsw@qq.com

Received 21 May 2019; Accepted 14 October 2019; Published 16 November 2019

Academic Editor: Valeria Vignali

Copyright ( ) 2019 Bin Han et al. This is an open access article distributed under the Creative Commons Attribution License, which permits unrestricted use, distribution, and reproduction in any medium, provided the original work is properly cited.

\begin{abstract}
This study investigated the influencing rules of curing temperature $\left(5,10,16\right.$, and $\left.20^{\circ} \mathrm{C}\right)$, cement ratio $(8 \%, 10 \%, 12 \%$, and $14 \%)$, and mass concentration $(70 \%, 73 \%, 74 \%$, and $75 \%)$ on the strength of backfill. In addition, a scanning electron microscope (SEM) is employed to analyze the microtopography of the backfill. Experimental results indicate that the uniaxial compressive strength (UCS) of the backfill decreases as the curing temperature diminishes; temperature substantially influences the earlier strength of backfill (it is much significant below $10^{\circ} \mathrm{C}$ ). In addition, as the cement ratio rises, the critical point for the impact of temperature on strength gradually moves toward a low-temperature zone; in pace with the slurry mass concentration increase, the compressive strength of the backfill also rises and its rate of increase enlarges after going beyond the critical concentration. In case the curing temperature is lower than $10^{\circ} \mathrm{C}$, the extent of hydration is also low inside the backfill. Through experiments, the critical concentration of slurry in the Jinying gold mine is determined as $73 \%$, and the critical interval of the cement ratio ranged between $10 \%$ and $12 \%$. Corresponding measures can be taken to increase the strength of backfill in the Jinying Gold Mine by $129.9 \%$. As a result, backfill collapse is effectively controlled.
\end{abstract}

\section{Introduction}

The filling mining method plays an extremely important part in controlling ground pressure, maintaining stope stabilization, improving ore recovery ratio, and protecting ecological environment [1-3]. The total area of the alpine region in China is 2.891 million $\mathrm{km}^{2}$. Their altitudes are between 1,500 and $5,000 \mathrm{~m}$, and the daily average temperature all year round is lower than $10^{\circ} \mathrm{C}$. As for resource reserve, it has $50 \%$ of China's total reserves. Owing to large-scale mining, the mineral resources in the alpine region are increasingly, constantly exploited, and the filling mining method is also gradually applied on mining in such regions. However, a lowtemperature alpine environment is a massive challenge to the application of this technology. The low-temperate high-humid climate of underground stope substantially affects the properties of slurry solidification and dehydration, especially the mechanical properties of the backfill.
The mechanical property of a backfill is a key and hot point for current research on the filling mining technology. However, these recent research studies mainly concentrate on the mechanical properties of backfill in normal temperature [4-8]. Through experiments, Thomas [8] found that a temperature lower than $10^{\circ} \mathrm{C}$ can greatly influence backfill strength. Some predecessors also explored the hydration and strength development characteristics of backfill with different sulfate contents in curing temperatures of 2 , 20,35 , or $50^{\circ} \mathrm{C}$. The corresponding results indicated that as the curing temperature rose, backfill strength linearly increased especially after the curing temperature goes beyond $20^{\circ} \mathrm{C}$, wherein the increase rate of backfill strength also rises. In contrast, the content of hydration products in the backfill, especially the tobermorite content, decreases as temperature drops, which fundamentally causes the backfill mechanical property to crack [9-12]. Zhang [13] studied the impacts of the curing strategies on the mechanical properties of cement 
mortar, and the results showed that the curing temperature significantly influences the earlier strength of the mortar with a minor influence on its later strength. Liu et al. and Zhao et al. [14, 15] adopted a response surface method to optimize the fill blending ratio for alpine mines and pointed out that slurry performances are enhanced as the curing temperature rose. In addition, when the temperature is below $5^{\circ} \mathrm{C}$, backfill strength is improved by increasing the slurry mass concentration and cement ratio.

The Jinying Gold Mine is located north of Baishan City, Jilin Province. The annual average temperature ranges from -3 to $7^{\circ} \mathrm{C}$ in the mining area, and the winter temperature under the shaft is about $5^{\circ} \mathrm{C}$ on average. In this mine, the high sublevel subsequent filling mining method is adopted, and exploitation is carried out in line with a stopping sequence from the chamber to the pillar. The corresponding daily output of ores is about 2,000 t. After terminating phase 1 stope mining, tailing is used for filling. At the time of pillar mining during the second phase, the backfill stability in phase 1 stope critically influenced safety and mine loss dilution indicators during pillar exploitation. Nevertheless, the quality of backfill in the Jinying Gold Mine remains questionable and frequent collapses occur (Figure 1). This is a massive potential safety hazard to mining operation.

The low strength of backfill and other problems encountered during waste cementing backfill in the cold region of Jinying Gold Mine serves as the current research background. Furthermore, the influencing rules of temperature on developing the strength of waste cementing backfill are explored based on the mixture ratio experiment, and the influencing rules of cement ratio and slurry mass concentration on the backfill strength are analyzed. In addition, scanning electron microscope (SEM) is also employed to analyze waste cementing backfill morphologies. An optimal waste cementing backfill mixture ratio required by the high sublevel subsequent filling mining method is proposed. Through in situ tests, the requirements of the present mining method for the filling technology and backfill strength are satisfied.

\section{Materials and Methods}

2.1. Backfill Material Selection. The filling materials selected for the experiment mainly consisted of tailings from the Jinying Gold Mine and waste rocks that developed underground. The curves formed by size fractions of tailings are shown in Figure 2(a); contents of -74 and $-20 \mu \mathrm{m}$ reach $75.57 \%$ and $43.2 \%$, respectively. In addition, it is $30.53 \mu \mathrm{m}$ for $D_{50}$. Clearly, tailings fall into a category of medium tailings. Coarse aggregate come from breccia wastes produced by tunneling ( $\mathrm{UCS}=76.33 \mathrm{MPa})$. In line with experimental requirements, they are broken into coarse aggregates of $-5 \mathrm{~mm}$ by a small jaw crusher. The curves formed by the corresponding size fractions are shown in Figure 2(b), where $D_{50}$ is $0.53 \mathrm{~mm}$. The 32.5 ordinary Portland cement is used as the cementing agent.

\subsection{Experiment Scheme Design of Backfill Mixing Ratio.} In situ experiment is carried out for the influencing factors on backfill strength in low temperature. On the one hand,

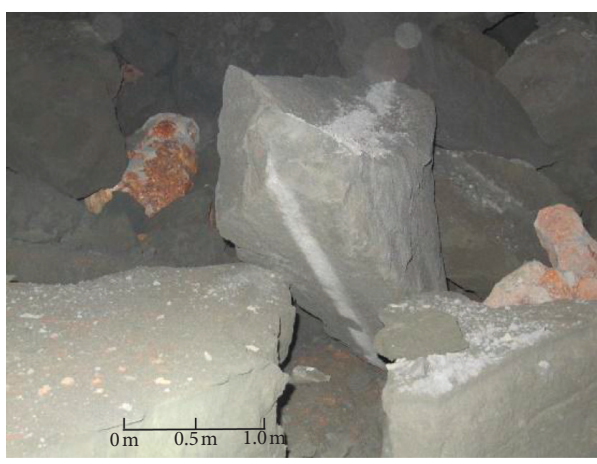

FIgURE 1: Underground backfill collapsing.

the impact of curing temperature on the strength of backfill is emphatically studied; on the other hand, the impacts of slurry mass concentration and cement ratio on this strength are also considered.

The curing temperatures adopted for the experiment are 5, 10, 16, and $20^{\circ} \mathrm{C}$. Among them, experiments are performed in a downhole curing room at $10^{\circ} \mathrm{C}$ or a laboratory at $16^{\circ} \mathrm{C}$. In addition, for 5 and $20^{\circ} \mathrm{C}$, the experiment is conducted in a curing box. A curing method with multiple combinations is employed here to consider the actual filling environment of the mine at the time of studying the impacts of temperature. The mass concentrations of slurry are $70 \%$, $73 \%, 74 \%$, and $75 \%$ (mass concentration is the percent taken from the solid mass in the total mass of slurry); cement ratios are $8 \%, 10 \%, 12 \%$, and $14 \%$ correspondingly. During the experiment, the proportion between waste rocks and tailings is $3: 1$, and the relevant slurry curing period is 7 or 28 days. Up to such a period, uniaxial compressive strength (UCS) test and microtopography observation are both carried out.

2.3. Experiment Methods and Process. The slurry is prepared according to the experiment design. The slurry is placed in a $\Phi 80 \mathrm{~mm} \times 200 \mathrm{~mm}$ die trial after uniform stirring (see Figure 3). As pouring filling samples have low strength at the initial phase of curing, curing should last $24 \mathrm{~h}$ for samples with pouring completed in a laboratory (curing temperature $=16^{\circ} \mathrm{C}$ ) to prevent samples from being damaged when they are transported to the downhole. When the samples are sufficiently strong, they can be transported to the downhole curing room (temperature $=10^{\circ} \mathrm{C}$ and humidity $=85 \%$ ). Under other temperature conditions, the samples are maintained in a curing box. Once the sample curing fulfills a preset period, these samples are cut into standard samples of $\Phi 80 \mathrm{~mm} \times 160 \mathrm{~mm}$. Subsequently, a $100 \mathrm{kN}$ universal press is utilized to test the UCSs of the filling body samples with a curing period of 7 or 28 days. The required pressure speed is between 0.05 and $0.1 \mathrm{kN} / \mathrm{s}$, as shown in Figure 4 . In addition, SEM is also adopted to observe microtopography of filling objects with a typical mixture ratio.

\section{Test Result Analysis}

3.1. Temperature Influence on Backfill Strength. The cement content added in slurry is $8 \%, 10 \%, 12 \%$, and $14 \%$. In case 


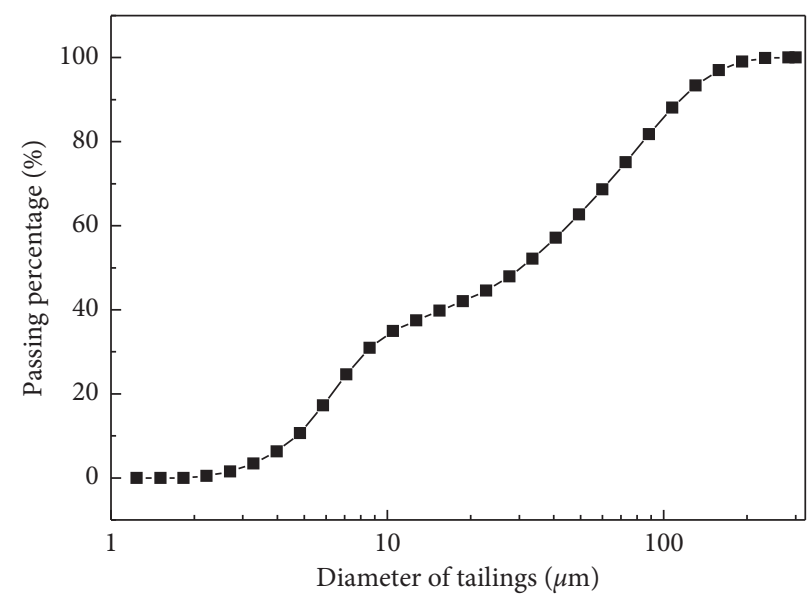

(a)

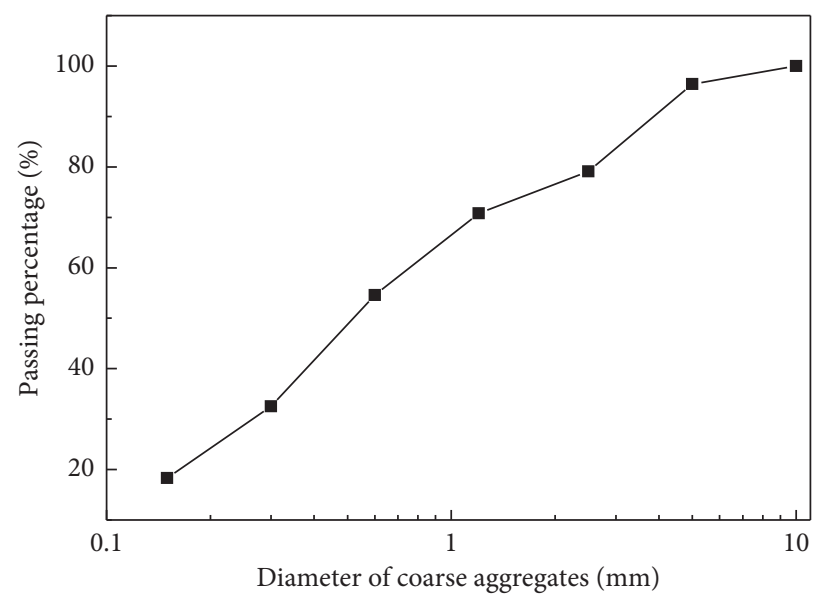

(b)

FIGURE 2: Granular composition curve of the backfill material: (a) granular composition curve of tailings; (b) granular composition curve of coarse aggregates.

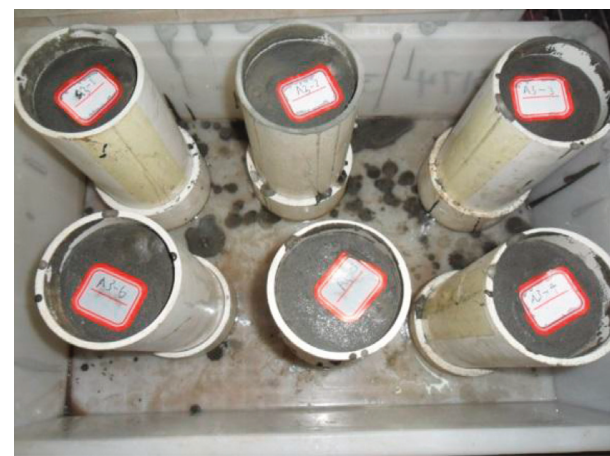

FIGURE 3: Sample preparation.

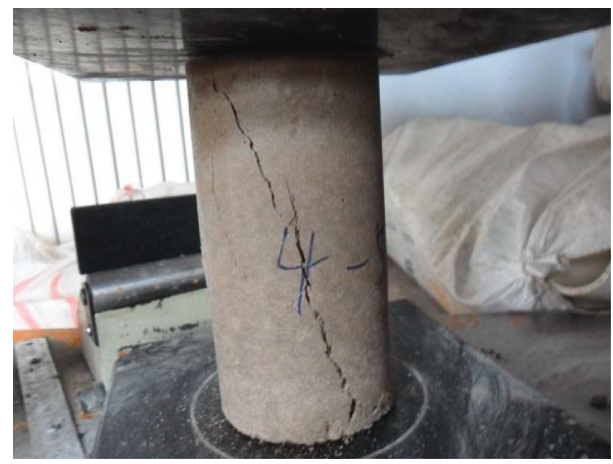

FIGURE 4: Strength test for backfill samples.

the curing temperature is $5,10,16$, or $20^{\circ} \mathrm{C}$, the UCS of backfill samples with a curing period of 7 or 28 days is separately tested; the corresponding results are given in Table 1.

In any cement content, the UCS of backfill with a curing period of 7 or 28 days kept increasing together with the rise of the curing temperature [16]. This finding is in basic consistency with concrete [17-20]. Figure 5 shows that the UCS with a curing period of 7 days slowly grows when cement content is low (8-10\%) and curing temperature is below $10^{\circ} \mathrm{C}$. However, if the curing temperature is beyond $10^{\circ} \mathrm{C}$, especially when higher than $16^{\circ} \mathrm{C}$, the UCS with a curing period of 7 days rapidly goes up. For example, when the cement content is $10 \%$, the strength of the backfill increases to $0.803 \mathrm{MPa}$ at $20^{\circ} \mathrm{C}$ from the original $0.259 \mathrm{MPa}$ at $10^{\circ} \mathrm{C}$. In contrast, in the case that such cement content is lower than the high level (10-14\%), the inflection point for the impact of temperature on backfill strength continuously moves toward the low-temperature zone. In other words, backfill strength substantially goes up after the curing temperature exceeds $10^{\circ} \mathrm{C}$. According to Figure 6, the impacts of temperature on the later backfill strength with a curing period of 28 days are less significant than its influences on that with a curing period of 7 days. Especially in the low-temperature section, its impacts on later compressive strength escalate. For example, when cement content is $10 \%$ and curing temperature rises from 5 to $10^{\circ} \mathrm{C}$, the compressive strength of the backfill with a curing period of 28 days goes up from 0.851 to $1.617 \mathrm{MPa}$ with a corresponding increase rate of $0.077 \mathrm{MPa} /{ }^{\circ} \mathrm{C}$. Concerning curing under low temperatures, changes in temperature tremendously affect the rise of the later backfill strength. Furthermore, critical point for temperature influence gradually moves toward the low-temperature zone as cement content rises $[21,22]$.

At the same temperature, the UCS of the backfill with a curing period of 7 or 28 days increases as cement content rises. When it goes up from $8 \%$ to $10 \%, 10 \%$ to $12 \%$, or $12 \%$ to $14 \%$, the UCS of the backfill at $10^{\circ} \mathrm{C}$ is $0.106,0.142$, or $0.314 \mathrm{MPa}$, respectively, with a curing period of 7 days; if the temperature is $16^{\circ} \mathrm{C}$, it becomes $0.183,0.258$, and $0.287 \mathrm{MPa}$, correspondingly. As for the backfill with a curing period of 28 days, its UCS increment is $0.378,0.252$, or $0.427 \mathrm{MPa}$ for $10^{\circ} \mathrm{C}$ and $0.704,0.296$, or $0.46 \mathrm{MPa}$ for $16^{\circ} \mathrm{C}$. This phenomenon indicates that, within an identical cement content increase interval, the UCS increment of the backfill during high-temperature curing is larger than that during lowtemperature curing. When the curing temperature is below $10^{\circ} \mathrm{C}$, the earlier compressive strength of the backfill with a 
TABLE 1: Impact of curing temperature on backfill strength (75\% wt.).

\begin{tabular}{|c|c|c|c|c|c|c|}
\hline \multirow{2}{*}{ Cement dosage (\%) } & \multirow{2}{*}{ Curing condition } & \multicolumn{2}{|c|}{ UCS } & \multirow{2}{*}{ Curing condition } & \multicolumn{2}{|c|}{ UCS } \\
\hline & & $7 \mathrm{~d} / \mathrm{MPa}$ & $28 \mathrm{~d} / \mathrm{MPa}$ & & $7 \mathrm{~d} / \mathrm{MPa}$ & $28 \mathrm{~d} / \mathrm{MPa}$ \\
\hline 8 & \multirow{4}{*}{ Curing box $\left(5^{\circ} \mathrm{C}\right)$} & 0.083 & 0.252 & \multirow{4}{*}{ Lab condition $\left(16^{\circ} \mathrm{C}\right)$} & 0.312 & 0.592 \\
\hline 10 & & 0.131 & 0.364 & & 0.495 & 1.296 \\
\hline 12 & & 0.226 & 0.537 & & 0.753 & 1.592 \\
\hline 14 & & 0.486 & 0.832 & & 1.04 & 2.052 \\
\hline 8 & \multirow{4}{*}{ Underground curing room $\left(10^{\circ} \mathrm{C}\right)$} & 0.153 & 0.473 & \multirow{4}{*}{ Curing box $\left(20^{\circ} \mathrm{C}\right)$} & 0.589 & 0.815 \\
\hline 10 & & 0.259 & 0.851 & & 0.803 & 1.617 \\
\hline 12 & & 0.401 & 1.103 & & 1.052 & 2.073 \\
\hline 14 & & 0.715 & 1.53 & & 1.357 & 2.622 \\
\hline
\end{tabular}

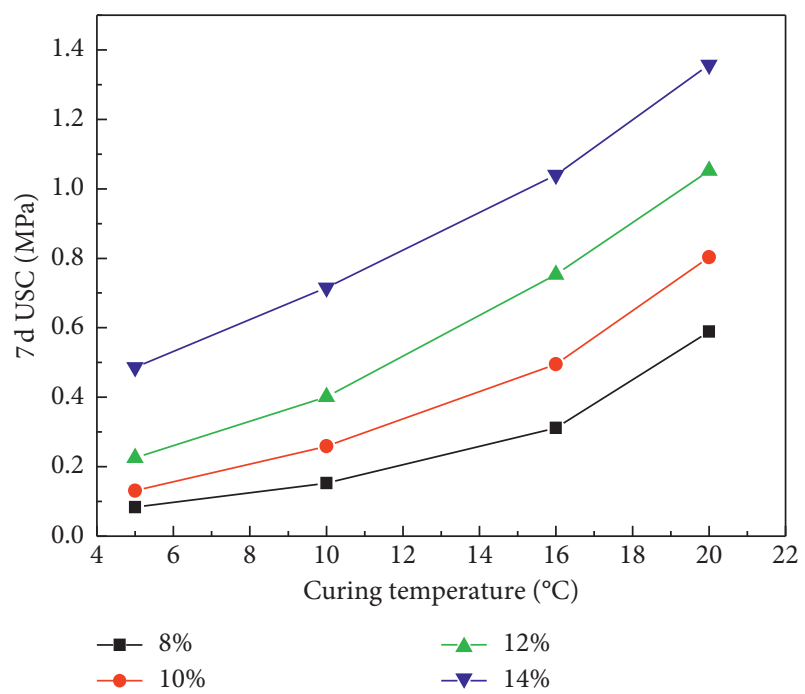

FIgURE 5: UCS at the curing temperature of 7 days.

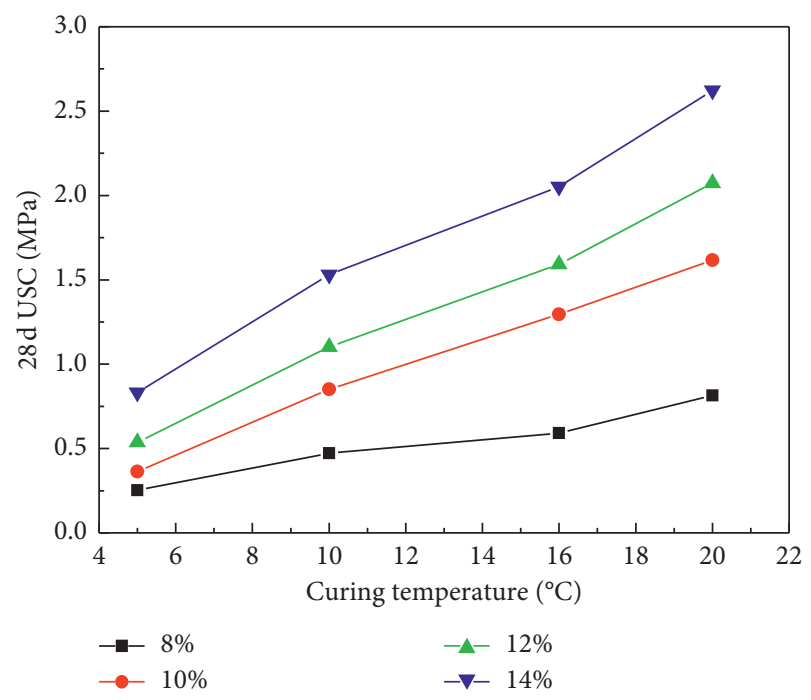

Figure 6: UCS at the curing temperature of 28 days.

curing period of 7 days is subjected to severe influences of cement content. The maximum backfill strength increment is obtained when the cement content is over $12 \%$. For the later strength with a curing period of 28 days, the strength variations incurred by cement content suffer from far less temperature impacts than earlier compressive strength of that in a curing period of 7 days. With regard to low cement content (below 10\%), the later strength of the backfill is greatly influenced by temperature. Therefore, the strength development of backfill is a result generated by the combined effects of curing temperature and cement content. With the increase in cement content, temperature influence on backfill strength gradually reduces. Considering this, backfill strength can be improved by bringing cement content up indirectly in low temperature.

3.2. Influence of Slurry Mass Concentration on Backfill Strength. Apart from the backfill strength under the impact of cement content, the mass concentration of slurry is also another important influencing factor $[23,24]$. The influence of slurry mass concentration on backfill strength is tested at $10^{\circ} \mathrm{C}$. Relevant results are given in Table 2 .

Based on experimental results, the UCS of the backfill with a curing period of 7 or 28 days rises as the mass concentration of slurry increases. In addition, a critical mass concentration also exists; after exceeding it, the backfill strength sharply rises. In case of diverse cement contents, a significant difference lies in the strength development of backfill. Figures 7 and 8 indicate that the backfill strength in a curing temperature of $10^{\circ} \mathrm{C}$ is extremely low when the slurry mass concentration is $70 \%$. Moreover, the UCS with a curing period of 7 or 28 days is only 0.278 or $0.619 \mathrm{MPa}$ separately if cement content is $14 \%$. Once the slurry mass concentration increases to $73 \%$, the increment of UCS with a curing period of 7 or 28 days is minor. Especially when the cement content is lower than $10 \%$, backfill strength increment is significantly lower than that generated when it is higher than $10 \%$. The critical point for slurry mass concentration is $73 \%$. If such a mass concentration goes beyond $73 \%$, the backfill strength can abruptly rise. Critical interval for cement content ranges from $10 \%$ to $12 \%$. When the interval is larger than any value within this range, strength significantly rises as mass concentration increases; in comparison, if smaller, strength increase rate drops. Therefore, the waste cementing backfill in the Jinying Gold Mine should be provided with a minimum mass concentration of more than $73 \%$. On the premise of guaranteeing its conveying property, the slurry mass concentration is improved to the greatest extent.

3.3. Microstructure Analysis. The microstructure of the backfill dramatically impacts its macromechanical characters [25-27]. A 
TABLE 2: Impact from slurry mass concentration to backfill strength $\left(10^{\circ} \mathrm{C}\right)$.

\begin{tabular}{|c|c|c|c|c|c|c|}
\hline \multirow{2}{*}{ Cement dosage (\%) } & \multirow{2}{*}{ Mass concentration (\%) } & \multicolumn{2}{|c|}{ UCS } & \multirow{2}{*}{ Mass concentration (\%) } & \multicolumn{2}{|c|}{ UCS } \\
\hline & & $7 \mathrm{~d} / \mathrm{MPa}$ & $28 \mathrm{~d} / \mathrm{MPa}$ & & $7 \mathrm{~d} / \mathrm{MPa}$ & $28 \mathrm{~d} / \mathrm{MPa}$ \\
\hline 8 & \multirow{4}{*}{75} & 0.153 & 0.473 & \multirow{4}{*}{73} & 0.066 & 0.17 \\
\hline 10 & & 0.259 & 0.851 & & 0.121 & 0.263 \\
\hline 12 & & 0.401 & 1.103 & & 0.268 & 0.684 \\
\hline 14 & & 0.715 & 1.53 & & 0.384 & 0.993 \\
\hline 8 & \multirow{4}{*}{74} & 0.118 & 0.346 & \multirow{4}{*}{70} & 0.035 & 0.102 \\
\hline 10 & & 0.207 & 0.421 & & 0.082 & 0.131 \\
\hline 12 & & 0.325 & 0.964 & & 0.157 & 0.306 \\
\hline 14 & & 0.513 & 1.411 & & 0.278 & 0.619 \\
\hline
\end{tabular}

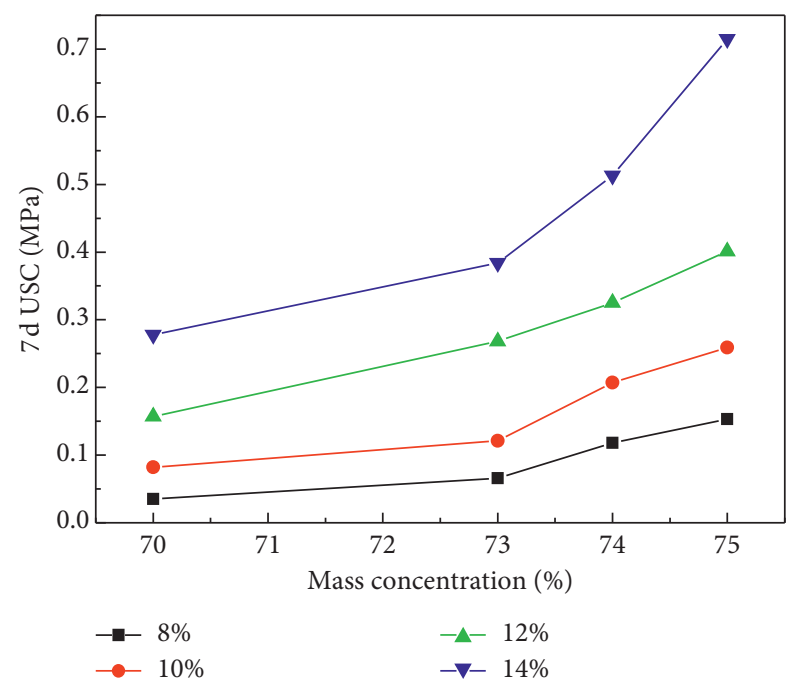

FIGURE 7: UCS of the mass concentration at 7 days.

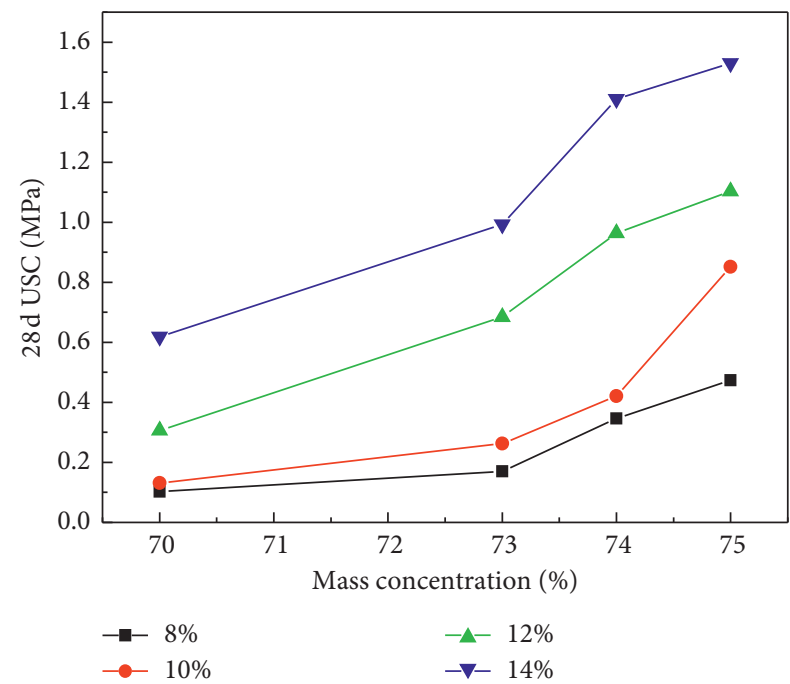

Figure 8: UCS of the mass concentration at 28 days.

good microstructure is the underlying reason behind the rather high earlier strength of the backfill. SEM is adopted here to analyze the microstructure of the backfill with diverse mixture ratios and under the combined effects of temperature, concentration, and cement. In this manner, their influencing mechanism on the macrostrength of the backfill can be probed.

Figure 9(a) is a SEM image with a slurry mass concentration of $74 \%$, a curing period of 7 days, and a curing temperature of $5^{\circ} \mathrm{C}$; Figure $9(\mathrm{~b})$ is another SEM image with a slurry mass concentration of $75 \%$, a curing period of 7 days, and a curing temperature of $10^{\circ} \mathrm{C}$; Figure $9(\mathrm{c})$ is another SEM image with a slurry mass concentration of $75 \%$, a curing period of 7 days, and a curing temperature of $16^{\circ} \mathrm{C}$; and Figure $9(\mathrm{~d})$ is another SEM image with a slurry mass concentration of $75 \%$, a curing period of 28 days, and a curing temperature of $16^{\circ} \mathrm{C}$.

Backfill structures with diverse mixture ratios are generally significantly different from each other; its microstructure of low mass concentration and low curing temperature contains numerous pores with an aperture size evidently larger than that of the backfill with high mass concentration and curing temperature. The major reasons are impacts of particle intensity and cement hydration reaction degree. Figure 9 demonstrates that no hydration reactions occur to the vast majority of cement particles in low concentration and temperature (Figure 9(a)), and tailing particles are locally coated with Aft generated at the early hydrating period of cement. As for tobermorite (C-S$\mathrm{H})$ that plays a major role in strength, its content is very low. In addition, tailing particles and hydration products cannot be effectively bonded together. As a consequence, no complete three-dimensional space structure is formed and large pores are observed. As slurry mass concentration and curing temperature increase (Figures 9(b) and 9(c)), the hydration products in the backfill also gradually multiply, and the corresponding space truss structure is also perfected step by step. However, perfoliate cracks are still evident from the SEM image (Figure 9(b)). In Figure $9(\mathrm{~d})$, the backfill has the densest microstructure because of the high curing temperature $\left(16^{\circ} \mathrm{C}\right)$ and mass concentration (75\%) as well as the rather long curing period (28 days). Compared with other several groups, this microstructure is featured with a high degree of cement hydration and dense space structure. As a result, the corresponding backfill has a high macroscopic UCS. The low temperature, which influences backfill strength development, primarily delays cement hydration. Consequently, the microstructure of the backfill is loose, with low compressive strength. 


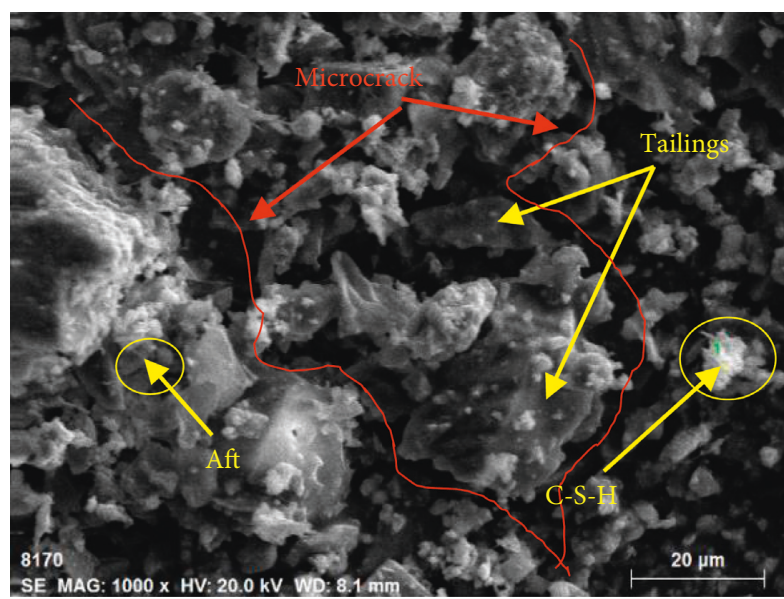

(a)

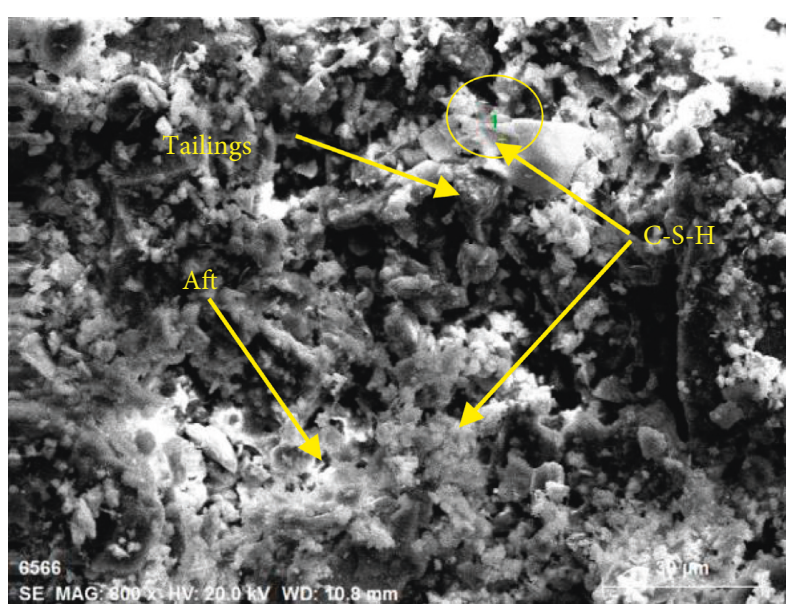

(c)

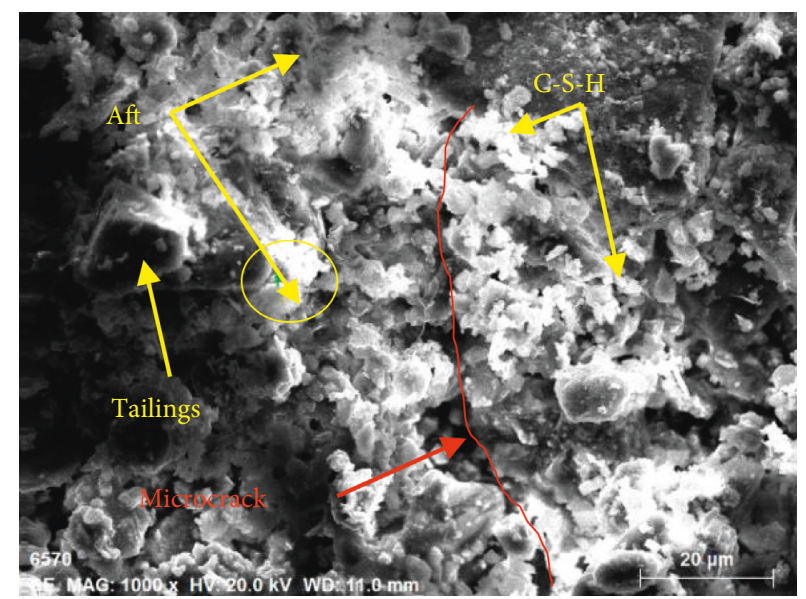

(b)

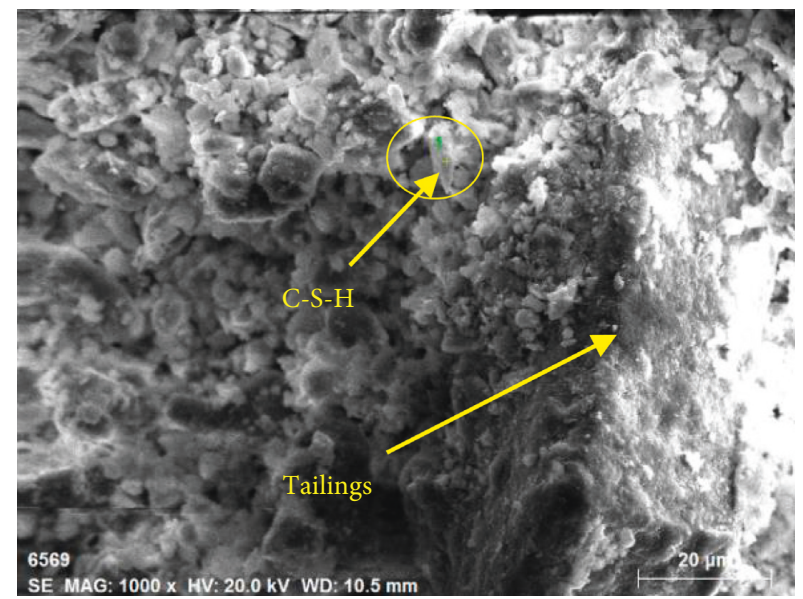

(d)

FIGURE 9: SEM picture of backfill varies relative to temperature and mass concentration (cement dosage at 10\%): (a) mass concentration at $74 \%, 7$ days, and $5^{\circ} \mathrm{C}$; (b) mass concentration at $75 \%, 7$ days, and $5^{\circ} \mathrm{C}$; (c) mass concentration at $75 \%, 7$ days, and $16^{\circ} \mathrm{C}$; (d) mass concentration at $75 \%, 28$ days, and $16^{\circ} \mathrm{C}$.

\section{Temperature Influence on Mechanism Analysis}

According to the above experimental results and previous research accomplishments, the impact of temperature on strength development of waste cementing backfill is mainly reflected in the cement hydration reaction rate, the backfill internal microstructure, and the evaporation and drying rate of slurry $[11,15,21,22]$. Temperature has two opposite effects on the waste cementing backfill. On the one hand, the rise of temperature can facilitate cement hydration, which benefits the strength development of backfill. On the other hand, temperature rise is accompanied by water evaporation rate increase, which reduces the water participating in the hydration reaction and prevents the completion of hydration. Therefore, temperature variations greatly influence the earlier strength of backfill with a minor influence on its later strength. Such a phenomenon is supported by experimental conclusions above. As for waste cementing backfill in a cold area, temperature influences mainly slows down the hydration rate instead of water evaporation. In addition, the influencing mechanism of temperature on cementing backfill strength can be described from several aspects below.

4.1. Pore Distribution Theory. As shown in Figure 9, backfill has a porous microstructure structure. Equation (1) is the relationship between backfill strength and porosity. In line with this, backfill strength exhibits a tendency of exponential decay as its internal increases. Therefore, the strength characteristics of backfill largely depend on its internal porosity [28-30]. Figure 9 shows that, with the increase in temperature, mass concentration, and curing period, the backfill microstructure pores gradually shrink as their density increases. As a result, the corresponding macrostrength also rises. Based on relevant researches, Goto pointed out that [31] the hydration reaction rate is accelerated in a cementing system as porosity keeps decreasing because of rising temperature. This finding conforms to the SEM observation results in this study. Thus, the rise of temperature that changes the porosity of waste cementing backfill is one of the factors influencing its strength development: 


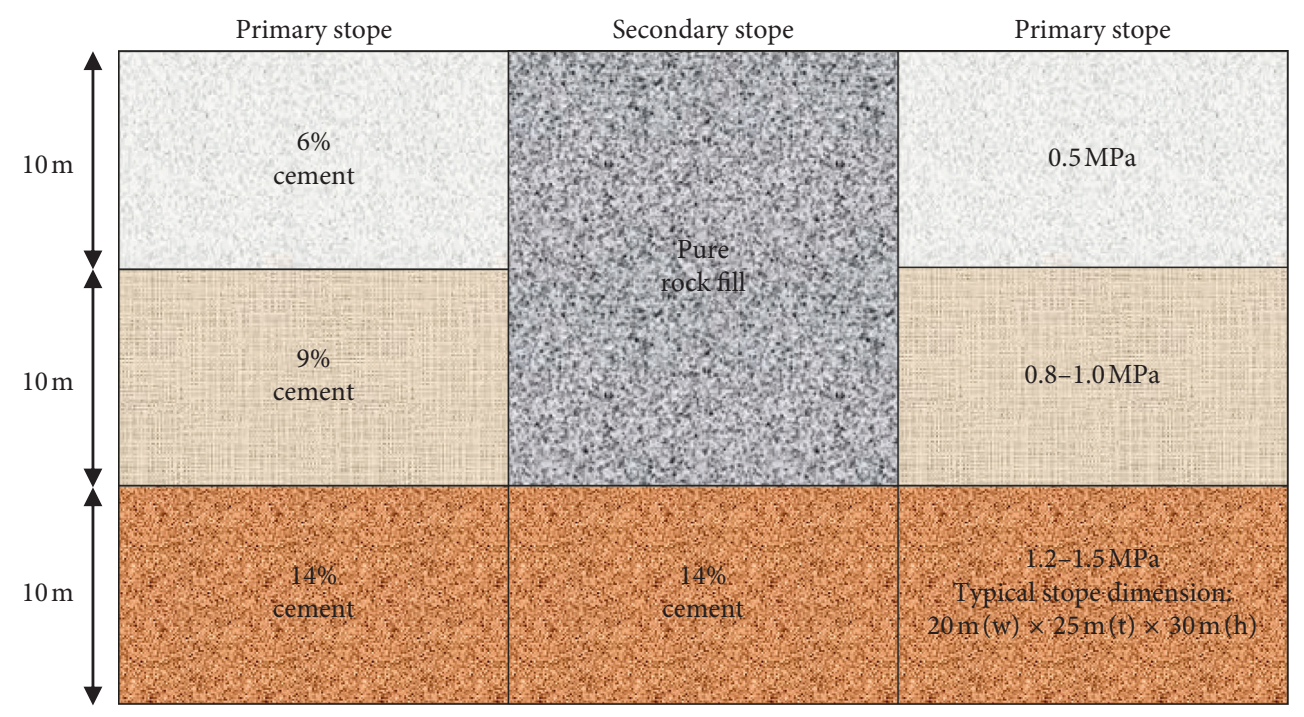

Figure 10: The Jinying Gold Mine backfill strength design to sublevel backfilled for later mining.

$$
S=S_{0} \exp (-b p)
$$

where $S$ is the strength of the backfill in an ideal condition, $S_{0}$ is the strength in the case of zero porosity, $b$ is the constant related to the gelling agent and the curing period, and $p$ is the internal porosity of the backfill.

4.2. Internal Dehiscence Theory. Once the stope is filled with slurry, a giant backfill can be formed (size of the stope in Jinying Gold Mine is $30 \mathrm{~m} \times 25 \mathrm{~m} \times 20 \mathrm{~m}$ ), and the cement inside the backfill continuously hydrates to accumulate heat. On this basis, temperature gradually climbs. However, in a cold area, temperature out of the stope can be extremely low that a significant temperature gradient transpires between the internal and external environments of the backfill. Thus, plastic continuously shrinks in the backfill. When its shrinkage is limited, tensile stress can be generated inside this backfill. Furthermore, if the stress goes beyond its tensile strength, cracks are formed inside it leading to backfill cracking; strength also decreases correspondingly [32, 33].

The analysis above clearly shows that the influence of temperature on waste cementing backfill is a complex physiochemical process and that the impact of temperature on the strength of waste cementing backfill in the Jinying Gold Mine is principally reflected in low-environment temperature for mining that affects cement hydration and creates few hydration products.

\section{Backfill Mix Ratio Optimization and Industrial Application}

5.1. Final Determination of Backfill Mix Ratio and Process Improvement. The typical stope size in the Jinying Gold Mine is $30 \mathrm{~m}$ (height) $\times 25 \mathrm{~m}$ (width) $\times 20 \mathrm{~m}$ (strike). For the cut and fill step, $10 \mathrm{~m}$ of high-density crown backfill is completed, and then $10 \mathrm{~m}$ of medium-strength backfill and $10 \mathrm{~m}$ of low-strength backfill are applied. For the second cut and fill step, $10 \mathrm{~m}$ of high-strength backfill is used for the

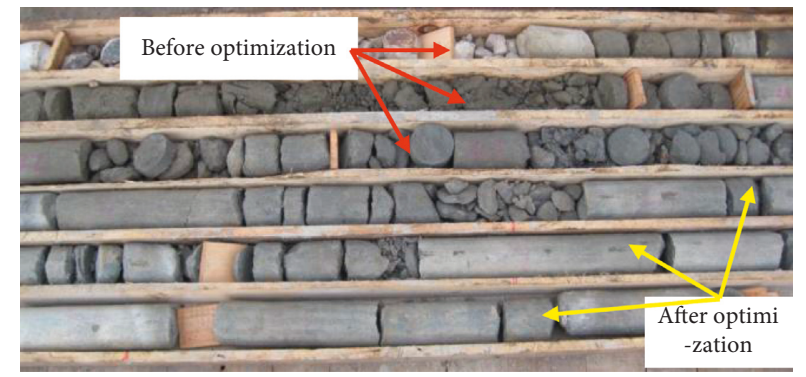

FIGURE 11: Comparison of backfill before and after optimization.

crown, and the rest is filled with full waste. According to the test result, the designed backfill strength for high strength is 1.2-1.5 MPa, with a cement dosage of $14 \%$; medium strength is designed as $0.8 \sim 1.0 \mathrm{MPa}$ with a cement dosage of $9 \%$; low strength is designed as $0.5 \mathrm{MPa}$ with a cement dosage of $6 \%$. For the above backfill designs, the mass concentration is the same, at $75 \%$. Figure 10 shows the backfill strength design.

During filling, the impact of temperature on backfill strength can be reduced by the measures below. First, filling materials (tailings, waste rocks, and cement) are placed indoor to preserve heat so as to guarantee that its temperature conforms to room temperature at the time of filling. Second, the underground water temperatures in winter or summer in the mine are both lower than $5^{\circ} \mathrm{C}$; consequently, backfill strength is certainly reduced. Considering this, hot water (no less than $30^{\circ} \mathrm{C}$ ) should be used for stirring during slurry preparation to guarantee effective cement hydration [20]. Finally, the underground ventilation system should be optimized to improve stope temperature and to benefit backfill strength development.

5.2. Site Industrial Experiment and Application Effect. Site demonstration shows that the combination of $-5 \mathrm{~mm}$ waste and tailings derives the maximum backfill strength. With a cement dosage of $14 \%$ and curing period of 28 days, 
1.74 MPa strength is achieved; a strength increase of $129.0 \%$ is attained compared with the previous application of iron mine tailings with the same cement slurry. The cost of the backfill material saves $1.8-2.0$ yuan $/ \mathrm{m}^{3}$. With optimized batching combinations, the backfill strength in the stope shows an obvious increase, indicating that it is an effective control measure for backfill failure during secondary drift stripping. Figure 11 shows the core drilling from the backfilled stope, depicting a significant improvement on backfill competency after optimization. Thus, controlling the adverse impact of temperature on the backfill can improve the later effectively, thereby enhancing mining efficiency.

\section{Conclusion}

Owing to backfill strength challenge of reducing at the Jinying Gold Mine, this paper investigated the impact of different parameters on the backfill strength buildup: temperature, cement dosage, and slurry mass concentration. Ideal results were achieved after experiment results were applied on the mine site. The achievements of this paper can be divided in the following aspects:

(i) The UCS of waste cementing backfill decreases as the curing temperature decreases, and the UCS at early stage of 7 days curing is distinctly influenced by temperature. When cement dosage increases, the critical point of temperature influence shifts to lowtemperature zones. When the curing temperature is lower than $10^{\circ} \mathrm{C}$, the UCS at the early stage of 7 curing days is severely influenced by cement dosage. The backfill strength can be improved by increasing cement dosage to offset the adverse influence of temperature.

(ii) The slurry mass concentration is one of the key factors influencing backfill strength in cold areas. As the concentration increases, the UCS rises accordingly, and the growing rate becomes more evident when the concentration exceeds the critical concentration. The Jinying Gold Mine has a backfill slurry critical concentration of $73 \%$ and a cement dosage threshold of 10-12\%.

(iii) The microstructure of the backfill significantly impacts the macromechanical performance of the backfill. The microstructure of the backfill was observed with SEM, through which we found that as the curing temperature, mass concentration, cement dosage, and curing period increases, the C-S-H content builds up and the spatial met structure of the backfill becomes more dense and solid. When curing temperature is lower than $10^{\circ} \mathrm{C}$, a large number of voids and penetrability cracks exist in the backfill.

(iv) The impact of temperature on backfill strength development is mainly demonstrated in the hydration speed, backfill internal structural properties, slurry evaporation, and drying speed. Limited hydration products lead to loose internal structure, increased porosity, and reduced strength. The temperature gradient between the inside and outside of the backfill results in the internal tension leading to cracks, which decreases backfill performance.

(v) By means of thermal insulation, heated water application, underground ventilation, and other measures for optimizing the backfill parameters and technology, the backfill strength of the Jinying Gold Mine was increased by $129.9 \%$ and the cost was reduced by 1.8-2 yuan/BCM compared to its previous practice, and the collapsing backfill during the second step of stoping was more effectively controlled.

\section{Data Availability}

The data used to support the findings of this study are included within the article.

\section{Conflicts of Interest}

The authors declare that they have no conflicts of interest regarding the publication of this paper.

\section{Acknowledgments}

The research was supported by the National Natural Science Foundation of China (Grant nos. 51964023, 11862010, and 51864023).

\section{References}

[1] W. Sun, H. Wang, and K. Hou, "Control of waste rock-tailings paste backfill for active mining subsidence areas," Journal of Cleaner Production, vol. 171, pp. 567-579, 2018.

[2] L. Liu, P. Yang, C. Qi, B. Zhang, L. Guo, and K.-I. Song, "An experimental study on the early-age hydration kinetics of cemented paste backfill," Construction and Building Materials, vol. 212, pp. 283-294, 2019.

[3] S. Cao, W. D. Song, and E. Yilmaz, "Influence of structural factors on uniaxial compressive strength of cemented tailings backfill," Construction and Building Materials, vol. 174, pp. 190-201, 2018.

[4] M. Fall, M. Benzaazoua, and E. G. Saa, "Mix proportioning of underground cemented tailings backfill," Tunnelling and Underground Space Technology, vol. 23, no. 1, pp. 80-90, 2008.

[5] W. Sun, A. Wu, K. Hou, Y. Yang, L. Liu, and Y. Wen, "Realtime observation of meso-fracture process in backfill body during mine subsidence using X-ray CT under uniaxial compressive conditions," Construction and Building Materials, vol. 113, pp. 153-162, 2016.

[6] S. Cao, G. Xue, and E. Yilmaz, "Flexural behavior of fiber reinforced cemented tailings backfill under three-point bending," IEEE Access, vol. 7, pp. 139317-139328, 2019.

[7] W. Sun, K. Hou, Z. Yang, and Y. Wen, "X-ray CT threedimensional reconstruction and discrete element analysis of the cement paste backfill pore structure under uniaxial compression," Construction and Building Materials, vol. 138, pp. 69-78, 2017.

[8] E. G. Thomas, Characteristics and Behaviour of Hydraulic Fill Material, University of Queensland, Brisbane, Australia, 1969. 
[9] M. Fall and S. S. Samb, "Effect of high temperature on strength and microstructural properties of cemented paste backfill," Fire Safety Journal, vol. 44, no. 4, pp. 642-651, 2009.

[10] M. Fall, J. C. Célestin, M. Pokharel, and M. Touré, "A contribution to understanding the effects of curing temperature on the mechanical properties of mine cemented tailings backfill," Engineering Geology, vol. 114, no. 3-4, pp. 397-413, 2010.

[11] M. Fall and M. Pokharel, "Coupled effects of sulphate and temperature on the strength development of cemented tailings backfills: Portland cement-paste backfill," Cement and Concrete Composites, vol. 32, no. 10, pp. 819-828, 2010.

[12] M. Pokharel and M. Fall, "Combined influence of sulphate and temperature on the saturated hydraulic conductivity of hardened cemented paste backfill," Cement and Concrete Composites, vol. 38, pp. 21-28, 2013.

[13] S. Z. Zhang, Q. Tian, J. J. Qiu et al., "Mechanical behavior of cement mortar in different curing methods," Concrete, vol. 61, pp. 20-130, 2012.

[14] L. Liu, C. Zhu, C. Qi, B. Zhang, and K.-I. Song, "A microstructural hydration model for cemented paste backfill considering internal sulfate attacks," Construction and Building Materials, vol. 211, pp. 99-108, 2019.

[15] G. Y. Zhao, L. Zhou, J. Ma et al., "Study on strength properties of cemented tailings backfill under low temperature condition," Mining and Metallurgical Engineering, vol. 33, pp. 2426, 2013.

[16] Z. Aldhafeeri, M. Fall, M. Pokharel, and Z. Pouramini, "Temperature dependence of the reactivity of cemented paste backfill," Applied Geochemistry, vol. 72, pp. 10-19, 2016.

[17] W. H. Price, "Factors influencing concrete strength," ACI Journal Proceedings, vol. 47, pp. 417-432, 1951.

[18] J. Kim, S. H. Han, and Y. C. Song, "Effect of temperature and aging on the mechanical properties of concrete Part I. Experimental results," Cement and Concrete Research, vol. 32, no. 7, pp. 1087-1094, 2002.

[19] P. Klieger, "Effect of mixing and curing temperature on concrete strength," ACI Journal Proceedings, vol. 54, pp. 1063-1081, 1958.

[20] M. Nasir, O. S. B. Al-Amoudi, H. J. Al-Gahtani, and M. Maslehuddin, "Effect of casting temperature on strength and density of plain and blended cement concretes prepared and cured under hot weather conditions," Construction and Building Materials, vol. 112, pp. 529-537, 2016.

[21] M. L. Walske, H. McWilliam, J. Doherty, and A. Fourie, "Influence of curing temperature and stress conditions on mechanical properties of cementing paste backfill," Canadian Geotechnical Journal, vol. 53, no. 1, pp. 148-161, 2015.

[22] L. Cui and M. Fall, "Mechanical and thermal properties of cemented tailings materials at early ages: influence of initial temperature, curing stress and drainage conditions," Construction and Building Materials, vol. 125, pp. 553-563, 2016.

[23] H. Lu, C. Qi, Q. Chen, D. Gan, Z. Xue, and Y. Hu, "A new procedure for recycling waste tailings as cemented paste backfill to underground stopes and open pits," Journal of Cleaner Production, vol. 188, pp. 601-612, 2018.

[24] L. Liu, Z. Fang, C. Qi, B. Zhang, L. Guo, and K.-I. Song, "Experimental investigation on the relationship between pore characteristics and unconfined compressive strength of cemented paste backfill," Construction and Building Materials, vol. 179, pp. 254-264, 2018.

[25] Y. He, Q. Chen, C. C. Qi, Q. L. Zhang, and C. Xiao, "Lithium slag and fly ash-based binder for cemented fine tailings backfill," Journal of Environmental Management, vol. 248, pp. 601-612, 2019.

[26] L. Liu, C. Zhu, C. Qi et al., "Effects of curing time and ice-towater ratio on performance of cemented paste backfill containing ice slag," Construction and Building Materials, vol. 228, Article ID 116639, 2019.

[27] Q. Sun, C. Cai, S. Zhang et al., "Study of localized deformation in geopolymer cemented coal gangue-fly ash backfill based on the digital speckle correlation method," Construction and Building Materials, vol. 215, pp. 321-331, 2019.

[28] L. Cui and M. Fall, "Multiphysics modelling of the behaviour of cemented tailings backfill materials," in Proceedings of the International Conference on Civil, Structural and Transportation Engineering, pp. 1-7, International ASET Inc., Ottawa, ON, Canada, 2015.

[29] L. Cui and M. Fall, "A coupled thermo-hydro-mechanicalchemical model for underground cemented tailings backfill," Tunnelling and Underground Space Technology, vol. 50, pp. 396-414, 2015.

[30] L. Cui and M. Fall, "Modeling and simulation of the consolidation behaviour of cemented paste backfill," in Proceedings of the Comsol Conference, pp. 1-5, Boston, MA, USA, October 2015.

[31] S. Goto and D. M. Roy, "The effect of w/c ratio and curing temperature on the permeability of hardened cement paste," Cement and Concrete Research, vol. 11, no. 4, pp. 575-579, 1981.

[32] J. K. Gao and C. X. Yang, "Deformation rule of wall rock and filling in deep stope in deposit2 of Jinchuan," Chinese Journal of Rock Mechanics and Engineering, vol. 22, pp. 2625-2632, 2003.

[33] F. H. Peng, S. L. Li, X. Q. Li, L. Zou, and H. Wang, "Deformation monitoring of bulky backfill in NO. 2 Mine area in Jinchuan," Chinese Journal of Rock Mechanics and Engineering, vol. 34, pp. 104-113, 2015. 


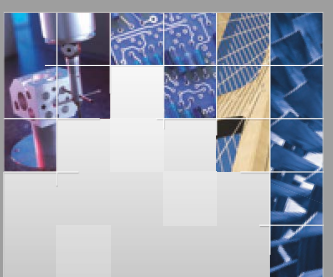

\section{Enfincering}
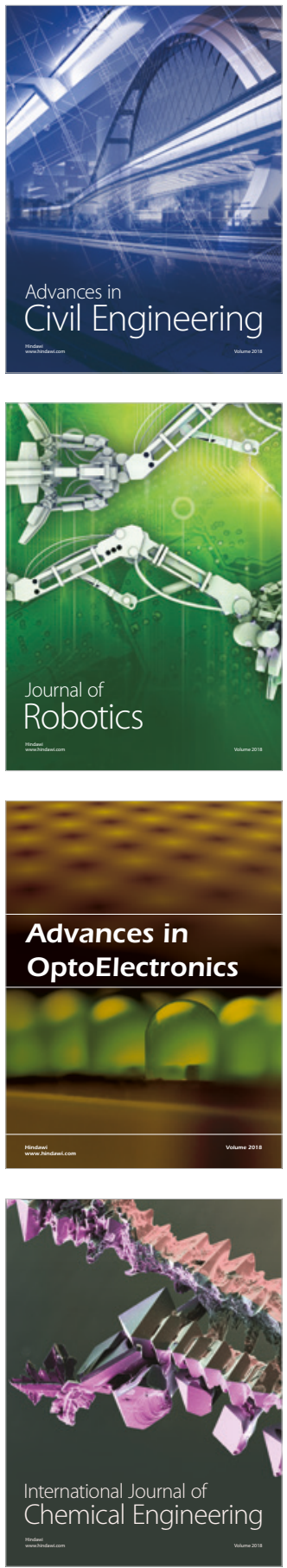

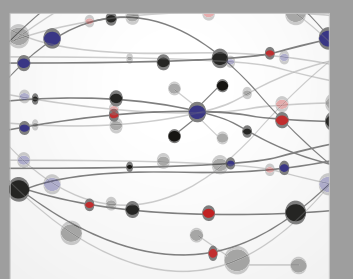

\section{Rotating \\ Machinery}

The Scientific World Journal

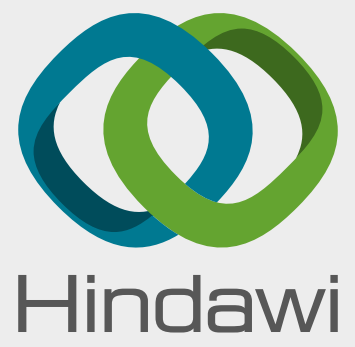

Submit your manuscripts at

www.hindawi.com
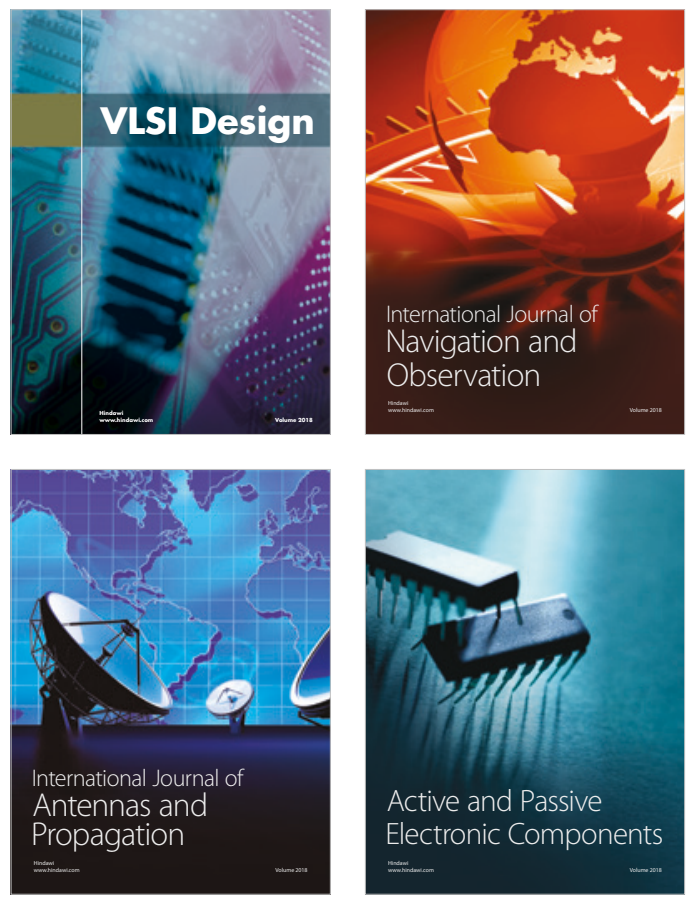
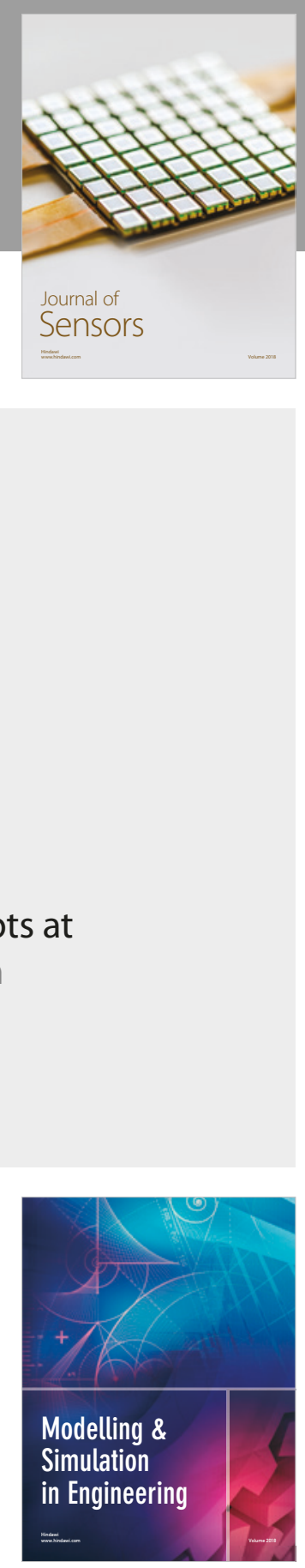

\section{Advances \\ Multimedia}
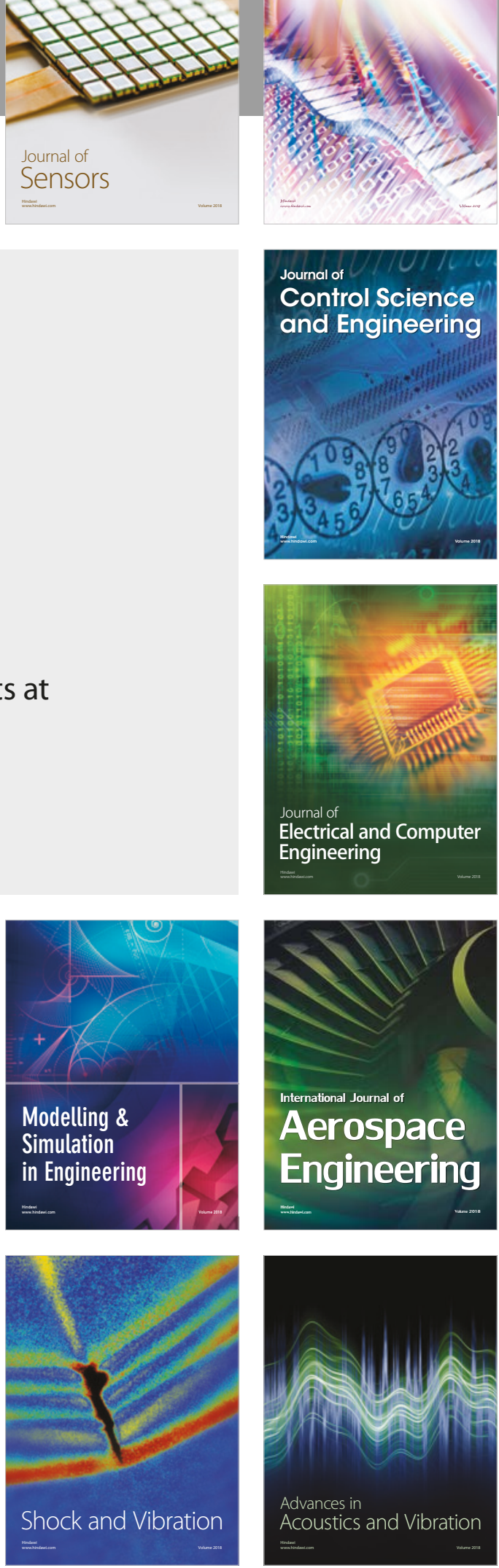